\title{
A difusão do pensamento de Michel Foucault na educação brasileira: um itinerário bibliográfico
}

JULIO GROPPA AQUINO

Universidade de São Paulo

Passadas mais de duas décadas e meia de seu desaparecimento, Michel Foucault persiste como um expoente do pensamento do pós-guerra, constituindo, segundo o historiador Paul Veyne (1982), o acontecimento capital do século XX do ponto de vista das ideias. Mesmo que não subscrevêssemos integralmente a estimativa de Veyne, haveríamos de reconhecer o vigoroso impacto de Foucault tanto no cenário intelectual quanto no cultural desde os anos de 1960, o que pode ser aferido pela quantidade incomensurável de livros, artigos, eventos etc. a ele dedicados em várias partes do planeta, incluindo o Brasil, conforme se atestará adiante.

O surgimento, em 2004 e em 2012, de dois periódicos específicos - respectivamente, Foucault Studies ${ }^{1}$ e Materiali Foucaultiani ${ }^{2}$ - ou a veiculação de um guia introdutório às suas ideias no formato de história em quadrinhos (Horrocks; Jevtic, 1999) são exemplos heterogêneos de uma popularidade que pouquíssimos intelectuais contemporâneos lograram obter, em escala global.

Aclamada por uns, execrada por outros e, ainda, objeto de contestação para alguns, a obra foucaultiana desdobra-se no intervalo exato de três décadas: com Doença mental e psicologia, de 1954, até os segundo e terceiro volumes de História

1 Disponível em: $<$ http://rauli.cbs.dk/index.php/foucault-studies/index>. Acesso em: 11 maio 2012.

2 Disponível em: <http://www.materialifoucaultiani.org/it/rivista/ultimo-numero.html>. Acesso em: 12 maio 2012. 
da sexualidade, em 1984; além dos 13 cursos por ele ministrados junto ao Collège de France e o conjunto de textos esparsos, como artigos, entrevistas, prefácios etc., publicados em sua quase totalidade nos Ditos e escritos (quatro volumes em francês; oito em português, até o momento). Três décadas de um tipo intensivo de pensamento cuja repercussão se faz notar de modo tão paulatino quanto recorrente em várias áreas de conhecimento - o que inclui a educação brasileira.

Visando contextualizar a reverberação do pensamento foucaultiano na literatura educacional brasileira, o presente trabalho tem como objetivo principal configurar um possível horizonte da difusão das ideias de Foucault na produção acadêmica levada a cabo na área, por meio da focalização de duas grandes frentes escriturais: os livros produzidos a partir de meados da década de 1990, bem como os artigos em periódicos divulgados entre 1990 e 2012.

Trata-se de dois âmbitos concretos que, supomos, compõem uma mostra fidedigna das linhas discursivas atuantes no campo. Isso porque o exame da difusão das ideias de um autor em determinada área do conhecimento pressuporia, em termos modelares, o manejo de uma simultaneidade de fontes: desde os estudos publicados na forma de livros (integrais ou capítulos) ou de teses e dissertações, até a bibliografia empregada em cursos universitários, passando pelos trabalhos apresentados em congressos e também, claro está, pelos artigos publicados em periódicos da área. Com efeito, cada um desses âmbitos congrega particularidades, podendo, inclusive, haver desníveis ou até incongruências quanto aos usos efetuados em cada um deles. Nessa perspectiva, o pesquisador que se empenhasse em analisar a complexidade envolvida na difusão de um autor nesse ou naquele quadrante estaria, salvo melhor juízo, impedido de imaginar que a somatória per se das fontes propiciaria alguma espécie de totalização do objeto em causa.

Abarcar a pluralidade de produções correlatas a um autor da envergadura e da circulação de Foucault revela-se, ademais, uma tarefa praticamente inexequível, dada a profusão de produções textuais que o tomaram, ora de modo pontual, ora de modo sistemático, como parâmetro temático, teórico e/ou metodológico. Exemplo disso são as teses e dissertações que dele se valeram explicitamente. Um levantamento sumário junto ao Banco de Teses da $\mathrm{Capes}^{3}$, no período entre 1987 e 2010, revela o impactante número de 1.791 dissertações e de 588 teses, perfazendo o total de 2.379 trabalhos de pós-graduação stricto sensu cujos resumos citam o pensador. Dentre tais trabalhos, 684 (510 dissertações e 174 teses) fazem referência concomitantemente aos termos Foucault e educação- quase um terço da produção total.

Assim, o pesquisador disposto a analisar as apropriações desse pensador seria forçosamente confrontado com a exigência de delimitação do corpus analítico que escolheu, uma vez que este seria acessível apenas por meio de estratos específicos, embora não excludentes entre si, mas tampouco obrigatoriamente interdependentes.

3 Disponível em: <http://capesdw.capes.gov.br>. Acesso em: 13 maio 2012. 
O mesmo raciocínio vale para o imperativo da delimitação temporal do corpus. Em nosso caso, focalizamos as duas últimas décadas, visto que o surgimento das produções sob o timbre foucaultiano na área educacional brasileira deu-se em meados dos anos de 1990. Assim, optamos por recuar até o início dessa década, de modo a contemplar as iniciativas germinais de interlocução com tal referencial.

Posto isso, cabe-nos, em primeiro lugar, traçar um percurso bibliográfico geral da difusão das ideias de Foucault no quadrante nacional para, em seguida, adentrar o circuito educacional.

\section{FOUCAULT NO BRASIL}

"Foucault foi incansável andarilho", assevera Heliana B. C. Rodrigues (2011, p. 98), pesquisadora da presença foucaultiana no país. As principais paragens do pensador incluem a Suécia, a Polônia, a Tunísia, o Japão, os Estados Unidos e o Irã. No Brasil, Foucault esteve em 1965, em 1973 e nos três anos seguintes. Rodrigues (2010) assinala o clima de tensão propiciado pela ditadura quando das duas passagens em que ele esteve em São Paulo, em 1965 e 1975; soma-se o embate teórico com os filósofos marxistas uspianos de então (Liudvik, 2011). De sua primeira passagem pelo Rio de Janeiro, em 1973, resultou um texto célebre, contendo as cinco conferências sobre $A$ verdade e as formas jurídicas proferidas junto à Pontifícia Universidade Católica (PUC) local, publicadas de modo artesanal no ano seguinte e republicadas, vinte anos mais tarde, em formato de livro.

Quando veio ao país pela última vez, em 1976, boa parte de sua obra já havia sido publicada na França, mas apenas os livros Arqueologia do saber e Doença mental e psicologia haviam sido traduzidos no Brasil; respectivamente, em 1972 e 1975. A propósito, a bibliografia de Foucault não seguiu, em nosso país, a ordem de publicação original. História da loucura na Idade Clássica, por exemplo, de 1961, teve sua primeira edição nacional em 1978; Nascimento da clínica, de 1963, em 1977; As palavras e as coisas, de 1966, em 1981; A ordem do discurso, de 1970, apenas em 1996.

Já a primeira referência nacional sobre o pensador, de 1971, intitulada $O$ homem e o discurso: a arqueologia de Michel Foucault, contendo textos de comentadores, além de uma entrevista do próprio pensador, é anterior à publicação de seus livros. Quanto aos periódicos, os dois levantamentos bibliográficos realizados sobre o tema (Alvarez; Prado Filho, 1995; Ferraz et al., 1985) revelam que os textos pioneiros são os de João P. Monteiro (1973), Roberto Machado (1974), José A. Giannotti (1979) e Laura Vergueiro (1979), todos eles ligados à área filosófica.

Não obstante a regionalidade das primeiras publicações brasileiras voltadas ao pensamento de Foucault, pode-se inferir que sua difusão por outros campos amplia-se a partir de 1977 e 1979, quando foram publicados, respectivamente, seus dois livros mais familiares ao público brasileiro: Vigiar e punir (hoje na 40a edição) e Microfísica do poder (na 25a edição). Este consiste numa compilação de textos selecionados por Roberto Machado, ele próprio um dos responsáveis pela divulgação de Foucault no país; é de sua autoria um dos textos inaugurais 
de esquadrinhamento do pensamento foucaultiano, a título de apresentação de Microfísica do poder (Machado, 1977).

Várias foram as obras - traduzidas ou de autores nacionais - que se dedicaram a introduzir os leitores brasileiros na seara das proposições foucaultianas. Os dois primeiros registros são também de 1977: Introdução ao pensamento de Michel Foucault, organizado por Angèle Kremer-Marietti, e Foucault, de Annie Guedez. Apenas em 1993 e, depois, em 2002, surgem duas produções nacionais afins: Para ler Michel Foucault, de Crisoston T. Vilas Boas, e Michel Foucault: um pensador do presente, de Marisa F. Eizirik. Em 2003, é publicado Foucault, de Pierre Billouet. Por fim, os livros mais recentes contendo um panorama geral da obra foucaultiana são o de Johanna Oksala, Como ler Foucault, de 2011, e o de André Constantino Yazbek, 10 Lições sobre Foucault, de 2012.

Duas outras obras traduzidas do francês e uma do espanhol, agora no formato de dicionários, constituem aquisições indispensáveis: Michel Foucault: conceitos essenciais e o Dicionário Foucault, ambos de Judith Revel, publicados respectivamente em 2005 e 2011. Soma-se a versão em português, em 2009, do Vocabulário de Michel Foucault: um percurso pelos seus temas, conceitos e autores, de Edgardo Castro - sem dúvida, uma referência capital para os estudos na área. ${ }^{4}$

Se, por um lado, a difusão do pensamento foucaultiano no país foi possível, ao menos em parte, graças às publicações introdutórias ou compilatórias a ele atinentes, por outro, é preciso levar em conta três outras fontes de disseminação bibliográfica do autor - de agora em diante, restritas apenas aos autores nacionais: 1 ) os dossiês e os números especiais de periódicos; 2) os eventos acadêmicos, na forma de colóquios, congressos etc., que geraram publicações; 3 ) as obras individuais que tiveram Foucault como matriz teórica, temática e/ou metodológica.

No primeiro caso, há registro de 16 publicações: a primeira, de 1989, a cargo de Manuscrito (v. XII, n. 2); depois, em 1994, o número inaugural da revista Escritos; no ano seguinte, o dossiê "Foucault: um pensamento desconcertante", junto à revista Tempo Social (v. 7, n. 1-2); um número dos Cadernos da FFC (v. 9, n. 1), em 2000, com o título "Michel Foucault: histórias e destinos de um pensamento"; um número da revista Psicologia Clínica (v. 13, n. 1), em 2001, intitulado "Foucault, 40 anos da História da Loucura"; dois números da revista Aulas (n. 3 e n. 7), em 2006 e 2010, respectivamente intitulados "Foucault" e "Foucault e as Estéticas da Existência"; o dossiê "Michel Foucault: múltiplas possibilidades" junto à revista Caminhos da História (v. 14, n. 2), em 2009; dois números da Revista de Filosofia Aurora, com os dossiês "Foucault/Deleuze" (v. 2, n. 28), de 2009, e "Parrhesia" (v. 23, n. 32), de 2011; um número de Cadernos Brasileiros de Saúde Mental, sob o título "Cinquenta anos de História da Loucura" (v. 3, n. 6), de 2011. Há, por fim, cinco dossiês, agora ligados especificamente a periódicos da área educacional, os quais serão discriminados adiante.

4 Devido à exiguidade do espaço e, ao mesmo tempo, ao elevado número de referências, não serão contempladas, no presente artigo, as obras traduzidas. 
Embora não se trate de um periódico acadêmico propriamente, $I H U$ on-line, revista do Instituto Humanitas da Universidade do Vale do Rio dos Sinos (UNISINOS), publicou por quatro vezes - em 2004 (n. 119), em 2006 (n. 203) e em 2010 (n. 343 e n. 344) - séries de entrevistas com estudiosos estrangeiros e nacionais da obra foucaultiana, reunidas sob os seguintes títulos: "Michel Foucault e as urgências da atualidade"; "Foucault 80 anos"; "O (des)governo biopolítico da vida humana"; e "Biopolítica, estado de exceção e vida nua".

Convém mencionar ainda, uma vez que se trata de veículos de amplo alcance, a revista Cult e seus três dossiês acerca da figura e do legado de Foucault em 2004 (n. 81), 2009 (n. 134) e 2011 (n. 159), bem como um número especial da Revista Educação (n. 3) sobre Foucault e a educação, e outro de Mente, Cérebro E̊ Filosofia (n. 6) dedicado a Foucault e Deleuze, ambos sem data informada, embora se saiba que datem de meados dos anos 2000.

O volume das publicações especializadas adensa-se quando são computadas as coletâneas derivadas de eventos acadêmicos, tendo as seguintes instituições como seus responsáveis ou que os sediaram: PUC, Universidade de São Paulo (USP), Universidade Estadual de Campinas (UNICAMP), Universidade Estadual Paulista (UNESP), Universidade Metodista de Piracicaba (UNIMEP), Universidade Federal do Rio de Janeiro (UFRJ), Universidade do Estado do Rio de Janeiro (UERJ), Universidade Federal de Minas Gerais (UFMG), Universidade Federal de Santa Catarina (UFSC), Universidade Federal do Rio Grande do Norte (UFRN), Universidade Federal de Uberlândia (UFU) e Faculdade de Direito de Campos. A seguir, são elencadas 22 referências dessa natureza, por ordem cronológica:

- Recordar Foucault: os textos do Colóquio Foucault (Ribeiro, 1985);

- Foucault vivo (Tronca, 1987);

- Foucault e a destruição das evidências (Mariguela, 1995);

- Michel Foucault: da arqueologia do saber à estética da existência (Castelo Branco; Neves, 1998);

- Retratos de Foucault (Castelo Branco; Portocarrero, 2000);

- Imagens de Foucault e Deleuze: ressonâncias nietzschianas (Rago et al., 2002);

- Michel Foucault entre o murmúrio e a palavra (Calomeni, 2004);

- Kafka-Foucault: sem medos (Passetti, 2004);

- Na companbia de Foucault: 20 anos de ausência (Passos; Belo, 2004);

- Michel Foucault:perspectivas (Falcão; Souza, 2005);

- Foucault e a autoria (Furlanetto; Souza, 2006);

- Foucault 80 anos (Kohan; Gondra, 2006);

- Figuras de Foucault (Rago; Veiga-Neto, 2006);

- O legado de Foucault (Scavone et al., 2006);

- Foucault hoje? (Queiroz; Cruz, 2007);

- Cartografias de Foucault (Albuquerque Júnior et al., 2008);

- Para uma vida não fascista (Rago; Veiga-Neto, 2009);

- Michel Foucault: sexualidade, corpo e direito (Souza et al., 2011); 
- Michel Foucault: filosofia Es política (Castelo Branco; Veiga-Neto, 2011);

- Michel Foucault: transversais entre educação, filosofia e história (Resende, 2011);

- Experimentadores: Michel Foucault e práticas historiográficas (Rosa et al., 2011);

- Foucault e o cristianismo (Candiotto; Souza, 2012).

Com relação aos estudos nacionais que tomaram Foucault como enquadre temático, teórico e/ou metodológico, destacam-se as obras Danação da norma: medicina social e constituição da psiquiatria no Brasil (Machado et al.,1978) e Ordem médica e norma familiar (Costa, 1979), ambas tidas como estudos seminais quanto à presença foucaultiana no pensamento nacional. A elas somam-se, na década seguinte, Foucault e a psicanálise (Chaves, 1988) e Ciência e saber: a trajetória da arqueologia de Michel Foucault (Machado, 1981).

E, no entanto, na década de 1990 e, especialmente, na de 2000 que o país testemunhará um aumento expressivo de publicações, no formato de livros, afiliadas ao universo foucaultiano, por nós categorizadas de acordo com três grandes frentes, dispostas cronologicamente:

1. Obras que se debruçam sobre tópicos foucaultianos específicos: Um pensamento infame: história e liberdade em Michel Foucault (Vaz, 1992); Michel Foucault e a idade do homem (Ternes, 1998); Amizade e estética da existência em Foucault (Ortega, 1999); Foucault: o paradoxo das passagens (Queiroz, 1999); Foucault, a filosofia e a literatura (Machado, 1999); Sujeito e laço social: a produção da subjetividade na arqueogenealogia de Michel Foucault (Paiva, 2000); A ética em Michel Foucault: a verdade, o sujeito, a experiência (Souza, 2000); Foucault e a crítica do sujeito (Araújo, 2001); O Dom Quixote de Foucault (Calmon, 2003); Michel Foucault e a constituição do sujeito (Fonseca, 2003); A analitica do poder em Michel Foucault: a arqueologia da loucura, da reclusão e do saber médico na Idade Clássica (Pereira, 2003); O presente, o intolerável... Foucault e a história do presente (Queiroz, 2004); Foucault, simplesmente: textos reunidos (Muchail, 2004); Michel Foucault: uma história da governamentalidade (Prado Filho, 2006a); Michel Foucault: uma bistória politica da verdade (Prado Filho, 2006b); Foucault e a resistência (Sampaio, 2006); Michel Foucault e a história genealógica em Vigiar e Punir (Vieira, 2006); Michel Foucault: a legitimidade e os corpos politicos (Braga Júnior, 2007); Poder, normalização e violência: incursões foucaultianas para a atualidade (Passos, 2008); Michel Foucault: o trajeto da voz na ordem do discurso (Souza, 2009); Foucault e a crítica da verdade (Candiotto, 2010); Biopolitica: as formulaçôes de Foucault (Farhi Neto, 2010); Michel Foucault e a ética do cuidado de si: desdobramentos históricos e desterritorialização da subjetividade (Soler, 2010); por fim, Foucault, mestre do cuidado: textos sobre A hermenêutica do sujeito (Muchail, 2011). 
2. Obras que relacionam Foucault e outros campos do saber ou temáticas não foucaultianas: $A$ ética como o cuidado de si e o poder pastoral na enfermagem (Lunardi, 1999); Entre cuidado e saber de si: sobre Foucault e a psicanálise (Birman, 2000); Michel Foucault e o direito (Fonseca, 2002); Nas pegadas de Foucault: apontamentos para a pesquisa de instituições (Pey et al., 2004); Foucault, história e anarquismo (Rago, 2004); Foucault e os dominios da linguagem: discurso, poder, subjetividade (Sargentini; Navarro-Barbosa, 2004); Foucault e a psicologia (Guareschi; Hüning, 2005); Michel Foucault: poder e análise das organizações (Silveira, 2005); Foucault e a fenomenologia (Nalli, 2006); Psicanálise e biopolitica: contribuição para a ética e a politica em Michel Foucault (Teshainer, 2006); Confissão e cura: uma interlocução entre Foucault e a psicanálise freudiano-lacaniana (Winter, 2006); Biopoder e direitos humanos: estudo a partir de Michel Foucault (Both, 2009); Poder e norma: Michel Foucault e a aplicação do direito (Lourenço, 2009); O problema do direito em Michel Foucault: entre imagens jurídicas e a proposta de um direito novo (Chaves, 2010); Foucault em casa: aspectos discursivos da construção da comunidade sul-americana de naçôes (2004-2006) (Vieira, 2010); e Michel Foucault e o direito (Rocha, 2011).

3. Obras que cotejam ou associam Foucault com outros autores: Para uma politica da amizade: Arendt, Derrida, Foucault (Ortega, 2000); A experiência do fora: Blanchot, Foucault e Deleuze (Levy, 2003); Foucault e Pêcheux na análise do discurso: diálogos E̋ duelos (Gregolin, 2006); Foucault com outros nomes: lugares de enunciação (Gomes; Souza, 2009); As ciências da vida: de Canguilhem a Foucault (Portocarrero, 2009); Vidas em risco: critica do presente em Heidegger, Arendt e Foucault (Duarte, 2010); Arte, vida e politica: ensaios sobre Foucault e Deleuze (Vasconcellos; Castelo Branco, 2010); além de Foucault e Deleuze/Guattari: corpos, instituições e subjetividades (Cardoso Júnior; Lemos, 2011).

O inventário bibliográfico apresentado até o momento não deixa dúvidas quanto ao fato de a presença foucaultiana no Brasil ter ocorrido de modo tão progressivo quanto abrangente. Cabe-nos, a partir de agora, pormenorizar a difusão de Foucault no campo educacional propriamente: um capítulo à parte da história da presença do pensador no país.

\section{FOUCAULT NA EDUCAÇÃO BRASILEIRA}

Por meio de um exame preliminar da ocorrência de textos cuja temática principal é a educação, presentes nos dossiês de periódicos e nas coletâneas gerais oriundas dos eventos acadêmicos, é possível subtrair um quadro fidedigno da paulatina repercussão das ideias do pensador francês no campo educacional brasileiro. Nos onze dossiês gerais publicados, respectivamente, pelas revistas Manuscrito (1989), Escritos (1994), Tempo Social (1995), Cadernos da FFC (2000), Psicologia 
Clinica (2001), Revista Aulas (2006 e 2010), Caminhos da História (2009), Revista de Filosofia Aurora (2009 e 2011) e Cadernos Brasileiros de Saúde Mental (2011), há registro de apenas dois artigos que tangenciam questões educacionais: "Por uma genealogia da adolescência” (César, 2000) e "Dicas...” (Veiga-Neto, 2010).

Contudo, nos cinco dossiês voltados à relação entre Foucault e a educação, encontrar-se-ão outros 31 textos da lavra de pesquisadores brasileiros ou de estrangeiros ligados a instituições nacionais. Dois dos cinco dossiês vieram a público, respectivamente, em 2004 e 2009, ambos em Educação E̋ Realidade. O primeiro, intitulado "Michel Foucault" (Dossiê, 2004), foi composto pelos seguintes textos redigidos por brasileiros: "Foucault, um diálogo", de Alfredo Veiga-Neto e Rosa M. B. Fischer; "Repensar a educação: Foucault", de Silvio Gallo; "Foucault e a educação: em defesa do pensamento", de José Ternes; "Instituição escolar e normalização em Foucault e Canguilhem", de Vera Portocarrero; "A emergência de um saber psicológico e as políticas de individualização”, de Henrique C. Nardi e Rosane N. Silva; "O conceito de dispositivo em Foucault: mídia e produção agonística de sujeitos-maternos", de Fabiana A. Marcello; "Na companhia de Foucault: multiplicar acontecimentos", de Rosa M. B. Fischer; e "Os Meninos", de Maura C. Lopes e Alfredo Veiga-Neto. Em tal dossiê, houve ainda outros quatro textos elaborados por estrangeiros.

Denominado "Governamentalidade e educação" (Seção Temática, 2009), o segundo dossiê contou com dez textos; seis deles de autores brasileiros. A saber: "Processos de governamentalização e a atualidade educacional: novas modulações normativas", de Julio G. Aquino e Cintya R. Ribeiro; "Governo dos corpos e escola contemporânea: pedagogia do fitness", de Maria Rita A. César e André Duarte; "O numerável, o mensurável e o auditável: estatística como tecnologia para governar", de Samuel E. L. Bello e Clarice Traversini; "Políticas de inclusão e governamentalidade", de Maura C. Lopes; "Governamentalidade neoliberal, teoria do capital humano e empreendedorismo", de Sylvio S. G. Costa; e "Modernidade líquida, capitalismo cognitivo e educação contemporânea”, de Karla Saraiva e Alfredo Veiga-Neto.

Em 2010, foi a vez de Educação Temática Digital publicar o dossiê "Foucault e a educação: é preciso pensar e agir de outros modos" (Dossiê, 2010), em que foram veiculados os artigos a seguir: "Para pensar de outros modos a modernidade pedagógica”, de Alfredo Veiga-Neto e Maura C. Lopes; "Michel Foucault e o 'cuidado de si': a invenção de formas de vida resistentes na educação", de Alexandre S. Freitas; "Exercícios ascéticos e práticas pedagógicas: por uma genealogia do poder disciplinar", de Ernani Chaves; "Foucault-Kant e a questão da Aufklärung como maioridade pedagógica”, de Claudio A. Dalbosco; "(Des)governos...: biopolítica, governamentalidade e educação contemporânea”, de Maria Rita A. César; "Notas sobre modernidade, pedagogia e infância a partir de Michel Foucault", de Haroldo de Resende; "Por uma interlocução interpelante entre Foucault e a psicanálise nas críticas às práticas educacionais", de Eduardo P. Silva; e "Do sedentarismo ao nomadismo: intervenções para se pensar e agir de outros modos na educação", de Alexandre F. Carvalho e Silvio Gallo. 
O penúltimo dos cinco dossiês, veiculado por Currículo sem Fronteiras em 2011, teve como título "Educar como arte de governar" (Seção Especial Temática, 2011) e foi composto por sete textos de autores ligados a instituições brasileiras e outros dois de estrangeiros. No caso dos primeiros, trata-se de: "Educar como arte de governar", de Alfredo Veiga-Neto e Karla Saraiva; "Educação, inclusão e reclusão", de Karla Saraiva e Maura C. Lopes; "Governamentalidade e violências", de Edson Passetti; "Do biopoder à governamentalidade: sobre a trajetória da genealogia do poder", de Antonio Maia; "Governo de si, cuidado de si", de Vera Portocarrero; "Discursos sobre formação de professores e arte de governar", de Karyne D. Coutinho e Luis H. Sommer; e "Natureza infantil e governamentalidade liberal", de Dora Marín.

A última iniciativa nessa mesma direção deu-se em 2012 por meio da seção intitulada "Biopolítica, governamentalidade e educação", publicada em Cadernos de Pesquisa (Tema em Destaque, 2012). Dentre seus três textos constitutivos, dois são de autores brasileiros: "Programas trainees corporativos e o governo das almas", de Jairo A. da Cruz e Karla Saraiva, assim como "Governamentalidade democrática e ensino de Filosofia no Brasil contemporâneo”, de Silvio Gallo.

Já no que diz respeito aos textos inseridos nas 22 coletâneas resultantes de eventos dedicados ao pensador francês, 26 deles evocaram direta ou indiretamente temáticas educacionais, sendo que 4 eram da lavra de autores estrangeiros. Somados, os 22 textos elaborados por autores nacionais perfazem menos de $5 \%$ do montante total dos escritos veiculados em tais coletâneas. São eles, em ordem cronológica:

- "Educação e governamentalidade neoliberal: novos dispositivos, novas subjetividades", de Alfredo Veiga-Neto (Castelo Branco; Portocarrero, 2000);

- “Coisas do governo...", de Alfredo Veiga-Neto (Rago et al., 2002);

- "Autoria: análise dos discursos dos alunos do ensino médio", de Rafaela L. V. Otte e Otília L. O. M. Heinig (Furlanetto; Souza, 2006);

- "Na oficina de Foucault", de Alfredo Veiga-Neto; "Foucault, a escola, a imprudência de ensinar", de José Ternes; e "Cuidar de si e cuidar do outro: implicações éticas para a educação dos últimos escritos de Foucault", de Silvio Gallo (Kohan; Gondra, 2006);

- "Dominação, violência, poder e educação escolar em tempos de Império", de Alfredo Veiga-Neto; e "Foucault: (re)pensar a educação", de Silvio Gallo (Rago; Veiga-Neto, 2006);

- "Foucault e as novas tecnologias educacionais: espaços e dispositivos de normalização na sociedade de controle", de Antonio B. N. T. Menezes; "Cartografando a gurizada da fronteira: novas subjetividades na escola", de Marisa V. Costa; e "Modos de subjetivação de professores afrodescendentes: técnicas de si ante práticas de inclusão/exclusão", de Marluce P. Silva (Albuquerque Júnior et al., 2008); 
- "O currículo e seus três adversários: os funcionários da verdade, os técnicos do desejo, o fascismo", de Alfredo Veiga-Neto; "(Des)educando corpos: volumes, comidas, desejos e a nova pedagogia alimentar”, de Maria Rita A. César; e "Do fascismo ao cuidado de si: Sócrates e a relação com um mestre artista da existência”, de Walter O. Kohan (Rago; Veiga-Neto, 2009);

- "O cuidado de si em Foucault e as suas possibilidades na educação: algumas considerações”, de Pedro A. Pagni (Souza et al., 2011);

- "Governamentalidades, neoliberalismo e educação", de Alfredo Veiga-Neto; "A governamentalidade nos cursos do Professor Foucault", de Carlos E. Noguera-Rodriguez; "A governamentalidade como plataforma analítica para os estudos educacionais: a centralidade da problematização da liberdade", de Julio G. Aquino; "As novas práticas de governo na escola: o corpo e a sexualidade entre o centro e as margens", de Maria Rita A. César; e "Norma, inclusão e governamentalidade neoliberal", de Maura C. Lopes (Castelo Branco; Veiga-Neto, 2011);

- "Função-educador: em busca de uma noção intercessora a favor de experiências de subjetividades ativas", de Alexandre F. Carvalho; e "O cruzamento entre a filosofia, a história e a educação na interpretação foucaultiana do diálogo Alcibiades", de Márcio A. Fonseca (Resende, 2011).

Por meio de tal panorama da produção textual, é possível obtermos um quadro razoavelmente nítido da gama de interesses temáticos dos estudiosos afiliados à abordagem foucaultiana no campo educacional, com destaque para a tópica da governamentalidade. A propósito, Alfredo Veiga-Neto é o autor, não por acaso, mais recorrente na literatura aí espelhada, uma vez que, ao lado de Tomaz Tadeu da Silva, foi um dos responsáveis por introduzir as ideias foucaultianas nos debates levados a cabo na educação nacional. O livro por ele organizado, intitulado Crítica pós-estruturalista e educação (Veiga-Neto, 1995) - coletânea de estudos de pesquisadores brasileiros, todos eles então ligados ao Programa de Pós-Graduação em Educação da Universidade Federal do Rio Grande do Sul (UFRGS), bem como O sujeito da educação: estudos foucaultianos - compilação de textos, em sua grande maioria, estrangeiros, sob organização de Tomaz Tadeu da Silva (1994) - constituem os marcos inaugurais da difusão das ideias do intelectual francês no quadrante educacional brasileiro.

A empreitada capitaneada por ambos os autores em meados dos anos de 1990 será a pedra angular daquilo que se convencionou designar pesquisas pós-críticas em educação, as quais terão a obra foucaultiana como um dos pilares primeiros de sustentação. Marlucy A. Paraíso (2004), autora de um estudo que visou situar historicamente o surgimento das investigações abrigadas sob tal designação junto aos registros dos encontros da Associação Nacional de Pós-Graduação e Pesquisa em Educação (ANPEd), afirma que a marca principal de tal modalidade investigativa refere-se às mudanças substantivas que elas operariam em relação às pesquisas críticas, as quais imprimiram o tom, senão hegemônico, ao menos predominante da investigação educacional até meados dos anos de 1900. A autora argumenta, ainda, 
que tais estudos incorporam "uma variedade de linguagens oriundas de diferentes autores e teorias" (Paraíso, 2004, p. 284). Dentre eles, a teorização foucaultiana ganha vulto como enquadre temático, teórico e/ou metodológico, seja de modo exclusivo, seja de modo conjugado com outros autores.

No caso dos livros, a literatura pedagógica da década de 1990 contará com importantes obras: Territórios contestados: o curriculo e os novos mapas políticos e culturais (Silva; Moreira, 1995); Alienígenas na sala de aula: uma introdução aos estudos culturais em educação (Silva, 1995); Poder-saber e ética da escola (Corazza, 1995); A escola (in)visivel: jogos de poder, saber, verdade (Eizirik; Comerlato, 1995); Gênero, sexualidade e educação: uma perspectiva pós-estruturalista (Louro, 1997); Liberdades reguladas: a pedagogia construtivista e outras formas de governo do eu (Silva, 1998) e O currículo como fetiche: a poética e a política do texto curricular (Silva, 1999).

Ainda nos anos de 1990 surge uma significativa série de publicações devotadas à explicitação de modos de pesquisar alinhados à vertente pós-estruturalista, contemplando aqueles orientados direta ou indiretamente pela teorização foucaultiana: Caminhos investigativos: novos olhares na pesquisa em educação (Costa, 1996), Caminhos investigativos II: outros modos de pensar e fazer pesquisa em educação (Costa, 2002) e Caminhos investigativos III: riscos e possibilidades de pesquisar nas fronteiras (Costa; Bujes, 2005).

No mesmo diapasão investigativo, vieram a público, na década de 2000, O que quer um currículo? Pesquisas pós-críticas em educação (Corazza, 2001); Infância e maquinarias (Bujes, 2002); Pedagogias criticas e subjetivação: uma perspectiva foucaultiana (Garcia, 2002); Foucault छ̋ a educação (Veiga-Neto, 2003); Livros de ocorrência: (in) disciplina, normalização e subjetivação (Ratto, 2007); Biopolítica, governamentalidade e educação: introdução e conexões, a partir de Michel Foucault (Gadelha, 2009); Foucault e a função-educador: sujeição e experiências de subjetividades ativas na formação humana (Carvalho, 2010); Foucault na educação (Valeirão, 2010); Pedagogia e governamentalidade ou Da Modernidade como uma sociedade educativa (Noguera-Ramirez, 2011); e o mais recente Trabalhar com Foucault: arqueologia de uma paixão (Fischer, 2012). É preciso destacar, ainda, as coletâneas dedicadas à relação entre Foucault e a educação: Um dispositivo chamado Foucault (Vasconcelos; Magalhães Júnior, 2002); Foucault, Deleuze É educação (Clareto; Ferrari, 2010); Diálogos em Foucault (Osório, 2010); Biopolitica, arte de viver e educação (Pagni et al., 2012); além dos dois volumes de Biopolitica, escola e resistência: infâncias para a formação de professores (Gadelha; Pulino, 2012; Oliveira; Kohan, 2012).

Ao oferecermos um inventário pormenorizado dos livros especializados disponíveis no país, nosso propósito circunscreveu-se à necessidade de dimensionar, o mais fidedignamente possível, um dos principais focos de difusão do pensamento de Foucault no campo educacional. ${ }^{5}$ Resta-nos, no entanto, perspectivar o impacto

5 A despeito de nosso trabalho se restringir à produção nacional, duas obras estrangeiras deveriam ser necessariamente referidas, dada sua circulação no país: O governo de si mesmo: modernidade pedagógica e encenaçôes disciplinares do aluno liceal (último quartel 
das ideias foucaultianas especificamente no âmbito dos periódicos nacionais - algo que, a nosso ver, ainda não foi efetuado nos estudos realizados na área, salvo aquele realizado por José G. Gondra (2005) e devotado ao campo da história da educação, o qual, no entanto, difere de nossa proposta no que tange à abrangência do corpus.

\section{FOUCAULT NA PESQUISA EDUCACIONAL BRASILEIRA}

A segunda fonte de escritos calcados no pensador francês, por nós selecionada, recobre os periódicos da área educacional, tendo em vista o fato de se tratar de um âmbito da literatura arbitrado por pares e de ampla circulação entre os pesquisadores. Ressalte-se que, nesse caso, a imersão em tal frente escritural demandou um conjunto de estratégias notadamente mais intrincadas do que aquelas empregadas na compilação dos livros.

Primeiro passo: a seleção dos periódicos. Foram eles: Cadernos CEDES; Cadernos de Pesquisa; Curriculo sem Fronteiras; Educação/PUCRS; Educação E̋ Realidade; Educação E Sociedade; Educação e Filosofia; Educação e Pesquisa; Educação em Revista; Educação Temática Digital; Educar em Revista; Pró-Posiçôes; Revista Brasileira de Educação; Revista Brasileira de Estudos Pedagógicos; e Revista Brasileira de História da Educação. Trata-se do conjunto das publicações periódicas mais consolidadas e bem avaliadas, de acordo com os sistemas de avaliação brasileiros. Convém esclarecer, entretanto, que não incluímos o periódico Teoria E̋ Educação, uma vez que, a despeito de sua importância no que diz respeito à divulgação de pensadores de matriz pós-estruturalista no país, sua circulação restringiu-se ao período entre 1990 e 1992.

Definida a constelação dos periódicos, o próximo passo consistiu na imersão em cada um dos volumes/números das 15 revistas selecionadas que, reunidos, totalizaram 698 fascículos no período das duas décadas focalizadas. Assim, o procedimento inicial consistiu no rastreamento dos textos que informaram, em suas referências bibliográficas, ao menos um dos textos de Foucault e que efetivamente o mencionaram no corpo da argumentação. Tal busca resultou no montante de 629 artigos. Descontados os 117 textos de autores estrangeiros, restaram então 512.

Em seguida, o processamento do material demandou a discriminação dos textos segundo três categorias distintas - a apropriaçâa incidental, a apropriação conceitual tópica e a apropriação do modo de trabalho - a reboque daquelas empregadas por Afrânio M. Catani, Denice B. Catani e Gilson R. M. Pereira (2001) na investigação realizada sobre as apropriações de Pierre Bourdieu no campo educacional, com a qual, aliás, nossa proposta investigativa se alinha quanto aos procedimentos gerais. Além dela, o referido estudo de José G. Gondra foi valioso para a triagem do material.

do século XIX - meados do século XX), de Jorge Ramos do Ó; e Por que Foucault?: novas diretrizes para a pesquisa educacional, sob organização de Michael A. Peters e Tina Besley. A primeira foi publicada em Portugal; a segunda foi traduzida no Brasil. 
Uma vez isolados os textos de acordo com as categorias indicadas acima, selecionamos apenas os estudos que tomaram o pensamento de Foucault explicitamente como modo de trabalho, chegando ao montante final de 132 artigos, assim distribuídos entre os periódicos analisados: Educação E̋ Realidade: 48; Revista Brasileira de Educação: 14; Educação Temática Digital: 14; Educação em Revista: 13; Currículo sem Fronteiras: 9; Educação e Pesquisa: 7; Educação छ Sociedade: 7; Cadernos de Pesquisa: 5; Pró-Posiçôes: 5; Educação e Filosofia: 3; Educação/PUCRS: 2; Educar em Revista: 2; Cadernos CEDES: 1; Revista Brasileira de Estudos Pedagógicos: 1; e Revista Brasileira de História da Educação: 1.

De nosso encontro com as fontes, uma série de dados reveladores pôde ser subtraída. O primeiro deles: a maior frequência de publicações relacionadas a Foucault é encontrada em Educação $\Xi$ Realidade, periódico ligado à UFRGS, em cuja Faculdade de Educação foram disparadas as pesquisas em torno do pensador francês e que, conforme se verá adiante, continua a sediá-las com regularidade. Em seguida, aparece um segundo grupo de revistas cuja produção de textos baseados em Foucault mantém-se na média de um terço daquela do periódico gaúcho; são elas: Revista Brasileira de Educação, Educação em Revista e Educação Temática Digital. Por sua vez, Currículo sem Fronteiras, Educação e Pesquisa, Educação É Sociedade, Cadernos de Pesquisa e Pró-Posições compõem um terceiro grupo dos periódicos, apresentando textos foucaultianos de modo esparso. O último grupo, composto por Educação e Filosofia, Educação/PUCRS, Educar em Revista, Cadernos CEDES, Revista Brasileira de Estudos Pedagógicos e Revista Brasileira de História da Educação, publicou o menor número de artigos sobre trabalhos que tiveram Foucault como referência principal; ao todo, oito textos.

No que diz respeito à cronologia das publicações, temos que o primeiro artigo explicitamente devotado ao pensamento foucaultiano veio a público em 1992, em Educação छ̋ Realidade. Trata-se de "O sujeito, a modernidade e a educação", de autoria de Nadja H. Prestes. De 1992 a 2000, foram publicados, ao todo, 16 textos - pouco mais de 10\% do total. Entre 2001 e 2005: 35 textos. Entre 2006 e 2010: 81 , equivalentes a $61 \%$ do total. Ou seja, nos últimos cinco anos analisados estão concentrados quase dois terços do total dos artigos - uma mostra irrefutável, portanto, do crescente interesse pela teorização foucaultiana na investigação educacional realizada no país.

Noventa e oito pesquisadores estiveram envolvidos na produção dos 132 artigos. Os mais assíduos, seja como autor exclusivo, seja como coautor, foram (por ordem decrescente): Rosa M. B. Fischer (12 textos); Alfredo Veiga-Neto (8); Marlucy A. Paraíso (6); Sandra M. Corazza (6); Maria Isabel E. Bujes (6); Paula C. Henning (5); Fabiana A. Marcello (5); Maria Manuela A. Garcia (4); Maura C. Lopes (4); Ana Lúcia S. Ratto (3); Clarice S. Traversini (3); Lisete Bampi (3); Luciana G. Loponte (3); Silvio Gallo (3); Adriana B. Leal (2); Alexandre F. Carvalho (2); Amadeu O. Weinmann (2); Cristianne M. F. Rocha (2); José G. Gondra (2); Maria C. R. F. Souza (2); Maria da Conceição F. R. Fonseca (2); Maria Rita A. César (2); Nadia G. S. Souza (2); e Vera H. F. Siqueira (2). Os demais autores, 74 ao todo, tiveram apenas um 
texto publicado no período analisado. Ainda e mais importante, os 24 autores acima arrolados foram responsáveis, seja individualmente, seja em coautoria, pela produção de 91 textos, equivalentes a $69 \%$ do montante total. Isso significa que apenas um quarto dos pesquisadores concentrou a produção de mais de dois terços da produção brasileira das pesquisas publicadas nos veículos por nós analisados.

Quanto à filiação institucional dos autores envolvidos, foram referidas, ao todo, 40 instituições, mormente universidades públicas. As mais frequentes foram: UFRGS (48 vezes); Universidade Luterana do Brasil (ULBRA) (12); UFMG (10); UNISINOS (9); Universidade Federal do Paraná (UFPR) (7); UNICAMP (6); Universidade Federal de Pelotas (UFPel) (6); e Universidade Federal do Rio Grande (FURG) (4).E, novamente, constata-se a concentração acentuada dos pesquisadores nas universidades do extremo sul do país (UFRGS, ULBRA, UNISINOS, UFPel e FURG), as quais somam pouco mais de $50 \%$ das filiações institucionais referidas.

No que toca aos usos da obra foucaultiana, três grandes vetores analíticos se descortinam: as obras de Foucault mais referidas; as temáticas e os tópicos teóricos mais visitados; por fim, os tipos investigativos empregados nas argumentações.

$\mathrm{Na}$ produção acadêmica educacional brasileira que tomou Foucault como modo de trabalho, saltam aos olhos algumas peculiaridades quanto à utilização do legado do autor francês. As obras mais referidas, nos 132 artigos, foram Vigiar e punir (69 vezes), História da sexualidade I (68) e $A$ arqueologia do saber (58); as duas primeiras obras foram citadas, portanto, em pouco mais da metade dos artigos. Um texto específico - "O sujeito e o poder" - foi citado 38 vezes. Em seguida, aparecem: História da sexualidade II (32); A ordem do discurso (28); As palavras e as coisas (24); História da sexualidade III (22); A verdade e as formas jurídicas (20); História da loucura na Idade Clássica (12): e, por fim, Nascimento da clínica (5). Quanto aos cursos proferidos por Foucault, são citados: Resumo dos Cursos do Collège de France (23); Em defesa da sociedade (20); A hermenêutica do sujeito (19); Segurança, território, população (13); Os anormais (11); Nascimento da biopolitica (8); e O governo de si e dos outros (3). Vale, ainda, mencionar o fato de que, dentre os livros de Foucault, Doença mental e psicologia teve apenas uma ocorrência, enquanto, curiosamente, Raymond Roussel não foi citado uma vez sequer.

Tal utilização da obra foucaultiana nas pesquisas educacionais brasileiras finda por revelar os tipos de interesse temático e teórico despertados entre os pesquisadores a ela devotados. No que se refere aos tópicos teóricos, os mais referidos pelos autores foram, em ordem decrescente: identidade/subjetividade/subjetivação; poder/relações de poder; governo/governamentalidade; disciplina/disciplinarização/ controle; (análise de) discurso; dispositivo; sexualidade; tecnologias (do eu); biopoder/biopolítica; e genealogia. Já no que diz respeito às temáticas específicas mais exploradas, temos a seguinte configuração, também em ordem decrescente: educação/ensino/escola; mídia/cinema; infância/criança, (a)normalidade/diferença/desigualdade; currículo/pedagogia; modernidade/pós-modernidade/pós-estruturalismo; formação; pesquisa educacional; inclusão/exclusão; história (da educação); corpo; gênero; adolescência/juventude; e cultura/cotidiano (escolar). 
Por fim, no que concerne ao approach metodológico das investigações realizadas, foi-nos possível isolar dois tipos gerais de procedimento, segundo o que foi informado pelos autores: ensaios e relatos de pesquisa. Enquadram-se, no primeiro caso, 82 dos 132 artigos; no segundo, os 50 restantes. Disso decorre que quase dois terços da produção brasileira de estudos educacionais de linhagem foucaultiana portam uma feição ensaística, delimitando, assim, o tom prevalente da discursividade aí em circulação. A diferença argumentativa, entre ambas as modalidades, residiria, no caso dos relatos de pesquisa, numa atenção analítica mais imediata a um problema específico, por meio do confronto com dados empíricos. Com efeito, as fontes mobilizadas nos 50 artigos que se enquadraram em tal categoria recobrem três diferentes tipos: 1 ) documentos (desde textos legais, programas governamentais e publicações oficiais até bibliografias de curso de formação de professores); 2) material audiovisual (programas de TV, filmes, revistas, jornais e internet); e 3) material narrativo obtido por meio de observação, depoimentos e/ou intervenção grupal.

Quanto aos ensaios, sua economia argumentativa costuma dar-se mais pelo desdobramento de determinadas ideias advindas das fontes teóricas, a título de interpretação do que ali se afigura como problema, e menos pelo exame de dados empíricos, embora algumas vezes deles decorra. Nos 82 ensaios analisados, a maior parte deles recupera as assertivas foucaultianas, seja para comentar, criticar ou reposicionar teoricamente determinadas problemáticas educacionais já assentadas no espectro bibliográfico (por exemplo: as políticas curriculares, os discursos sobre a infância etc.), seja para cotejá-las ou confrontá-las às ideias de outros autores (exemplos: Bauman, Freinet, Paulo Freire, Deleuze, Freud, Nietzsche etc.) no que se refere a seu enquadramento educacional. Outra frente argumentativa dos ensaios, embora menos frequente, é aquela dedicada a articular às coordenadas teóricas foucaultianas determinadas questões pontuais suscitadas por documentos oficiais e por material audiovisual.

Assim, enquanto os relatos de pesquisa parecem percorrer um caminho argumentativo apoiado, primordialmente, em fontes empíricas, os ensaios priorizam as fontes teóricas no enfrentamento de determinado problema. Nesse sentido, pode-se dizer que os ensaios se valem de uma discursividade mais centrípeta, isto é, mais enraizada no exame das ideias do próprio Foucault e suas extensões ou implicações para o campo educacional, ao passo que os relatos de pesquisa apresentam um movimento mais centrífugo, posto que mais fincado em determinadas injunções concretas não necessariamente antevistas no referencial teórico foucaultiano, o qual finda por ser empregado como crivo analítico daquilo com que ali se deparou.

\section{NOTAS CONCLUSIVAS: PARA ALÉM DA DIFUSÃO}

Ao estimar o impacto de um autor sobre determinado campo de conhecimento, são precisamente os modos de apropriação de suas ideias, e não apenas sua difusão, que se destacam como problema investigativo. Para tanto, seria preciso ter em mente uma precaução basilar: em vez de incorrer no ajuizamento dos usos (bons 
ou maus, adequados ou não, consistentes ou não etc.) que se fizeram das ideias do autor, mais producente seria proceder à contextualização problematizadora desses mesmos usos. Nessa perspectiva, a multiplicidade e a heterogeneidade das apropriações do legado foucaultiano afirmam-se como traços distintivos daquilo que alguns comentadores - por exemplo, Margareth Rago (1995) - denominam efeito-Foucault sobre determinadas áreas do conhecimento, em especial, aquelas ligadas às ciências sociais e humanas, incluída, claro está, a educação brasileira.

No que concerne ao emprego das ideias foucaultianas nesse quadrante, cumprir-nos-ia ter em mente uma questão de fundo consoante àquela que intitula um dos textos de Rosa M. B. Fischer (2003), a pesquisadora, como vimos, mais assídua no terreno das publicações em periódicos: "Foucault revoluciona a pesquisa em educação?”.

A resposta seria favorável caso pudéssemos reconhecer, em determinada produção textual, a presença de alguns critérios basilares, os quais se tivessem convertido, de algum modo, em atitudes metodológicas carreadas pelo pesquisador na abordagem a que se engajou. A saber:

Primeira delas, compreender que nossas lutas (e pesquisas) sempre têm a ver com linguagem, já que estamos continuamente envolvidos com lutas discursivas; segunda atitude, atentar para a ideia de que palavras e coisas dizem respeito a fatos e enunciados que, a rigor, são "raros", isto é, não são óbvios, estão para além das "coisas dadas"; terceira, que fatos e enunciados referem-se basicamente a práticas, discursivas e não discursivas, as quais constituem matéria-prima de nossas investigações, seja em que campo estas se concentrem, e dizem respeito sempre a relações de poder e a modos de constituição dos sujeitos individuais e sociais; finalmente, a atitude de entrega do pesquisador a modos de pensamento que aceitem o inesperado, especialmente aqueles que se diferenciam do que ele próprio pensa. (idem, p. 372-373)

Como se pode deduzir, a escrita investigativa na companhia de Foucault jamais se confinaria à mera subscrição de ditames temáticos, teóricos e/ou metodológicos já consagrados pelo próprio uso dos pesquisadores, em observância ao padrão universitário da aplicação mecânica, do comentário isento ou da adesão de véspera às assertivas do pensador, mas implicaria, nos termos de Veiga-Neto (2003), uma relação de fidelidade negativa com o que foi legado por ele. Trafegar no registro foucaultiano exigiria, assim, uma atitude antropofágica, à moda do que o próprio Foucault levou a cabo, por exemplo, em relação ao pensamento de Nietzsche.

Em outra passagem, Fischer (2005) relembra que, nos meandros da apropriação de um autor, o que está em curso é precisamente a reescrita de sua obra e, por conseguinte, sua continuação, fato este que facultaria uma arte de assinar o que se lê por meio da qual seria possível "vasculhar em suas formulações teóricas um ponto de encontro com nós mesmos, com aquilo que escolhemos como objeto, com aquilo em que nós investimos nossa vida, nosso trabalho, nosso pensamento" (idem, p. 120). 
Das proposições dos autores anteriores decorre, a nosso ver, uma interpelação acerca dos dilemas em torno da apropriação de Foucault pelos pesquisadores educacionais a ele alinhados, a qual, segundo Veiga-Neto e Fischer (2004), seria marcada por um uso convencional do legado do pensador francês, dando-se por meio da inclinação ao modismo, ao reducionismo, ao esquematismo, à adesão a slogans pseudoteóricos.

Crítica ainda mais severa é aquela de Tomaz Tadeu da Silva (2002) ao atestar um movimento que combinaria estagnação e ortodoxia no interior dos estudos de cunho pós-estruturalista, incluindo os de linhagem foucaultiana. Inventivos outrora, eles ter-se-iam aliado, mediante a falta de chamamento (auto)crítico, ao status quo, redundando paradoxalmente em catecismo, nos termos do precursor de tais estudos no Brasil.

Também Heliana B. C. Rodrigues (2011, p. 108) oferece um inquietante panorama dos modos que viriam marcando a apropriação do pensamento foucaultiano no país, crivados, a seu ver, por estratégias de controle materializadas pelos seguintes expedientes:

[...] o da citação decorativa e infinita; o da reverência ao mestre (por mais que mestre... a suspeita); o da dogmatização produtora de obediência e renúncia; o da monopolização por sociedades de eruditos; o dos "ismos" de ocasião, banalizadores e impotentizantes; o da disciplinarização sob fronteiras estritas (filosóficas, sociológicas, historiográficas... pouco importa); o das aproximações, sob a forma de "Foucault e...", nas quais o(a) eventual companheiro(a) serve para tornar Foucault mais respeitável (e, consequentemente, mais palatável). Aquele sobre quem tanto se contam pequenas histórias nada edificantes viverá hoje, em nosso país, somente em "boas companhias"?

A avaliação contundente da autora, ao esboçar um quadro normalizador dos usos de Foucault entre nós, oferece, no entanto, um amplo feixe de efeitos analíticos para um problema que, a todo tempo, esteve a perpassar o presente trabalho: a captura discursiva do autor de $A$ ordem do discurso operada pela educação brasileira.

Não obstante, é preciso esclarecer que a presente investigação restringiu-se, por ora, à contextualização do quadro geral da difusão - e não o da apropriação - do pensamento foucaultiano que se afirmou na literatura educacional das duas últimas décadas. Posto isso, resta-nos uma interrogação-chave como ponto de chegada de nosso percurso: quando se trata do Foucault forjado pela educação brasileira, estaríamos, afinal, diante de embotamentos, intermitências ou eternos recomeços? Ora, uma resposta honesta a tal questão contemplaria, talvez em igual proporção ou intensidade, os três movimentos acima.

Se partirmos da premissa do próprio Foucault, de que entre as palavras e as coisas não se estabelece uma relação de coextensividade ou de correspondência natural, mas de força e, a rigor, de imposição de sentidos - isto é, ao falarmos sobre as coisas, não as traduzimos ou revelamos, mas as forjamos -, seria preciso admitir que, por meio das próprias coisas ditas a respeito do pensador pelos especialistas da área 
educacional, deparamos com os contornos fáticos de mais um dos mil Foucaults de que fala seu biógrafo, Didier Eribon $(1990,1996)$; um Foucault portador de feições e trejeitos, sem dúvida, singulares, porém não peremptórios, tampouco definitivos.

Ao fim e ao cabo de nosso percurso investigativo, parece-nos inegável a existência de uma espécie de fagocitose operativa do legado foucaultiano - desde aquelas iniciativas de caráter instrumental até outras de vocação apologética - em curso na literatura educacional brasileira das duas últimas décadas. Daí que, por um lado, deparamos com um Foucault ornamental, tão banalizado quanto reverenciado; um Foucault paradoxalmente saturado pela função autor com a qual, aliás, ele se debateu sem cessar vida afora. Por outro lado, foi possível detectar, aqui e acolá, traços, ainda que descontínuos e amiúde evanescentes, de um Foucault recalcitrante, intempestivo, para sempre movente; um Foucault ainda samurai (Veyne, 2011), refratário a toda tentativa de domesticação, estereotipia e dogmatização epistemológicas, éticas ou políticas. Um Foucault livre ou, quiçá, liberto de seu próprio fantasma. Apenas uma bilha errante a ecoar na grande algaravia do mundo.

\section{REFERÊNCIAS}

Albuquerque Júnior, Durval M.; Veiga-Neto, Alfredo; Souza Filho, Alípio de (Orgs.). Cartografias de Foucault. Belo Horizonte: Autêntica, 2008.

Alvarez, Marcos C.; Prado Filho, Kléber. Michel Foucault. A obra e seus comentadores. Tempo Social, São Paulo: FFLCH/USP, v. 7, n. 1-2, p. 197-246, 1995.

Araújo, Inês L. Foucault e a crítica do sujeito. Curitiba: UFPR, 2001.

Birman, Joel. Entre cuidado e saber de si: sobre Foucault e a psicanálise. Rio de Janeiro: Relume-Dumará, 2000.

Bотн, Valdevir. Biopoder e direitos humanos: estudo a partir de Michel Foucault. Passo Fundo: IFIBE, 2009.

Braga Júnior, Marcos. Michel Foucault. a legitimidade e os corpos políticos. Barueri: Manole, 2007.

Bujes, Maria Isabel E. Infância e maquinarias. Rio de Janeiro: DP\&A, 2002.

Calmon, Jean. O Dom Quixote de Foucault. Rio de Janeiro: E-papers, 2003.

Calomeni, Teresa C. B. (Org.). Michel Foucault entre o murmúrio e a palavra. Campos: Faculdade de Direito de Campos, 2004.

CAndiotto, César. Foucault e a crítica da verdade. Belo Horizonte: Autêntica; Curitiba: Champagnat, 2010.

.; Souza, Pedro de (Orgs.). Foucault e o cristianismo. Belo Horizonte: Autêntica, 2012.

Cardoso Júnior, Hélio R.; Lemos, Flávia S. (Orgs.). Foucault e Deleuze/Guattari: corpos, instituições e subjetividades. São Paulo: Annablume, 2011.

Carvalho, Alexandre F. Foucault e a função-educador: sujeição e experiências de subjetividades ativas na formação humana. Ijuí: Unijuí, 2010. 
Castelo Branco, Guilherme; Neves, Luiz F. B. (Orgs.). Michel Foucault. da arqueologia do saber à estética da existência. Rio de Janeiro: NAU; Londrina: CEFIL, 1998.

.; Portocarrero, Vera (Orgs.). Retratos de Foucault. Rio de Janeiro: NAU, 2000. .; Veiga-Neto, Alfredo (Orgs.). Michel Foucault: filosofia \& política. Belo Horizonte: Autêntica, 2011.

Catani, Afrânio M.; Catani, Denice B.; Pereira, Gilson R. M. As apropriações da obra de Pierre Bourdieu no campo educacional brasileiro, através de periódicos da área. Revista Brasileira de Educação, Rio de Janeiro: ANPEd, n. 17, p. 63-85, maio/ago. 2001. CÉsar, Maria Rita A. Por uma genealogia da adolescência. In: Birolı, Flávia; Alvarez, Marcos C. (Orgs.). Michel Foucault: histórias e destinos de um pensamento. Cadernos da FFC [Faculdade de Filosofia e Ciências - UNESP], Marília, v. 9, n. 1, p. 131-148, 2000. Chaves, Ernani. Foucault e a psicanálise. Rio de Janeiro: Forense Universitária, 1988.

Chaves, João. O problema do direito em Michel Foucault: entre imagens jurídicas e a proposta de um direito novo. Curitiba: Juruá, 2010.

Clareto, Sônia M.; Ferrari, Anderson (Orgs.). Foucault, Deleuze Ėeducação. Juiz de Fora: UFJF, 2010.

Corazza, Sandra M. Poder-saber e ética da escola. Ijuí: Unijuí, 1995.

O que quer um currículo? Pesquisas pós-críticas em educação. Petrópolis: Vozes, 2001.

Costa, Jurandir F. Ordem médica e norma familiar. Rio de Janeiro: Graal, 1979.

Costa, Marisa V. (Org.). Caminhos investigativos: novos olhares na pesquisa em educação. Porto Alegre: Mediação, 1996.

(Org.) Caminhos investigativos II: outros modos de pensar e fazer pesquisa em educação. Rio de Janeiro: DP\&A, 2002.

.; Bujes, Maria Isabel E.(Orgs.). Caminhos investigativos III: riscos e possibilidades de pesquisar nas fronteiras. Rio de Janeiro: DP\&A, 2005.

Dossı̂̂ Foucault e a Educação: é preciso pensar e agir de outros modos. Educaşão Temática Digital, Campinas: UNICAMP, v. 12, n. 1, p. 147-302, dez. 2010.

Dossı̂̂ Michel Foucault. Educação \& Realidade, Porto Alegre: UFRGS, v. 29, n. 1, p. 5-239, jan./jun. 2004.

Duarte, André. Vidas em risco: crítica do presente em Heidegger, Arendt e Foucault. Rio de Janeiro: Forense Universitária, 2010.

Eizirik, Marisa F.; Comerlato, Denise. A escola (in)visivel: jogos de poder, saber, verdade. Porto Alegre: UFRGS, 1995.

Eribon, Didier. Michel Foucault. São Paulo: Companhia das Letras, 1990. Michel Foucault e seus contemporâneos. Rio de Janeiro: Jorge Zahar, 1996.

Falcão, Luis F.; Souza, Pedro de (Orgs.). Michel Foucault: perspectivas. Florianópolis: Achiamé, 2005. 
FARHi Neto, Leon. Biopolítica: as formulações de Foucault. Florianópolis: Cidade Futura, 2010.

Ferraz, Márcia C. S.; Junqueira, Vera Lúcia; Carvalho, Márcia N. dos Reis; Vale, Eunice do. Foucault: levantamento bibliográfico de artigos em periódicos. In: Ribeiro, Renato J. (Org.). Recordar Foucault. os textos do Colóquio Foucault. São Paulo: Brasiliense, 1985. p. 239-247.

Fischer, Rosa M. B. Foucault revoluciona a pesquisa em educação? Perspectiva, Florianópolis: UFSC, v. 21, n. 2, p. 371-389, jul./dez. 2003.

Escrita acadêmica: arte de assinar o que se lê.In: Costa,Marisa Vorraber; Bujes, Maria Isabel Edelweiss (Orgs.). Caminhos investigativos III: riscos e possibilidades de pesquisar nas fronteiras. Rio de Janeiro: DP\&A, 2005. p. 117-140.

Trabalhar com Foucault: arqueologia de uma paixão. Belo Horizonte: Autêntica, 2012.

Fonseca, Márcio A. Michel Foucault e o direito. São Paulo: Max Limonad, 2002.

Michel Foucault e a constituição do sujeito. São Paulo: EDUC, 2003.

Furlanetto, Maria Marta; Souza, Osmar de (Orgs.). Foucault e a autoria. Florianópolis: Insular, 2006.

Gadelha, Sylvio. Biopolitica, governamentalidade e educação: introdução e conexões, a partir de Michel Foucault. Belo Horizonte: Autêntica, 2009.

; Pulino, Lúcia (Orgs.). Biopolítica, escola e resistência: infâncias para a formação de professores. Campinas: Alínea, 2012.v. 1.

Garcia, Maria Manuela A. Pedagogias críticas e subjetivação: uma perspectiva foucaultiana. Petrópolis: Vozes, 2002.

Giannotti, José A. Histórias sem razão (sobre Michel Foucault). Encontros com a Civilização Brasileira, Rio de Janeiro, n. 16, p. 115-134, 1979.

Gomes, Daniel O.; Souza, Pedro de (Orgs.). Foucault com outros nomes: lugares de enunciação. Ponta Grossa: UEPG, 2009.

Gondra, José G. Paul. Michel Foucault: uma caixa de ferramentas para a história da educação? In: FARIA Filho, Luciano M. (Org.). Pensadores sociais e história da educação. Belo Horizonte: Autêntica, 2005. p. 285-309.

Gregolin, Maria do Rosário. Foucault e Pêcheux na análise do discurso: diálogos \& duelos. São Carlos: Claraluz, 2006.

Guareschi, Neuza M. F.; Hüning, Simone M. (Orgs.). Foucault e a psicologia. Porto Alegre: Abrapso Sul, 2005.

Horrocks, Chris; Jevtic, Zoran. Introducing Foucault. a graphic guide. London: Icon Books, 1999.

Kohan, Walter O.; Gondra, José (Orgs.). Foucault 80 anos. Belo Horizonte: Autêntica, 2006.

Levy, Tatiana S. A experiência do fora: Blanchot, Foucault e Deleuze. Rio de Janeiro: Relume-Dumará, 2003. 
Lıudviк, Caio. Foucault na USP. Cult, São Paulo: Editora Bregantini, n. 159, p. 40-42, 2011.

Lourenço, Frederico R. R. Poder e norma: Michel Foucault e a aplicação do direito. Porto Alegre: Núria Fabris, 2009.

Louro, Guacira L. Gênero, sexualidade e educação: uma perspectiva pós-estruturalista. Petrópolis: Vozes, 1997.

Lunardi, Valéria L. A ética como o cuidado de si e o poder pastoral na enfermagem. Pelotas: UFPel; Florianópolis: UFSC, 1999.

Machado, Roberto. A arqueologia do saber e a constituição das ciências humanas. Discurso, São Paulo: USP, v. 5, n. 5, p. 87-118, 1974.

Por uma genealogia do poder. In: Foucault, Michel. Microfísica do poder. Rio de Janeiro: Graal, 1977. p. VII-XXIII.

Ciência e saber: a trajetória da arqueologia de Michel Foucault. Rio de Janeiro: Graal, 1981.

Foucault, a filosofia e a literatura. Rio de Janeiro: Jorge Zahar, 1999.

.; Loureiro, Ângela; Luz, Rogério; Muricy, Kátia. Danação da norma: a medicina social e constituição da psiquiatria no Brasil. Rio de Janeiro: Graal, 1978.

Mariguela, Márcio (Org.). Foucault e a destruição das evidências. Piracicaba: UNIMEP, 1995.

Monteiro, João P. Discurso teórico e discurso retórico. Discurso, São Paulo: USP, v. 4, n. 4, p. 79-93, 1973.

Muchail, Salma T. Foucault, simplesmente: textos reunidos. São Paulo: Loyola, 2004.

Foucault, mestre do cuidado: textos sobre $A$ hermenêutica do sujeito. São Paulo:

Loyola, 2011.

Nalli, Marcos. Foucault e a fenomenologia. São Paulo: Loyola, 2006.

Noguera-Ramirez, Carlos E. Pedagogia e governamentalidade ou da modernidade como uma sociedade educativa. Belo Horizonte: Autêntica, 2011.

Oliveira, Paula R.; Kohan, Walter O. (Orgs.). Biopolítica, escola e resistência: infâncias para a formação de professores. Campinas: Alínea, 2012.v. 2.

Ortega, Francisco. Amizade eestética da existência em Foucault. Rio de Janeiro: Graal,1999. Para uma política da amizade: Arendt, Derrida, Foucault. Rio de Janeiro: Relume-Dumará, 2000.

Osório, Antônio C. N. (Org.). Diálogos em Foucault. Campo Grande: Oeste, 2010.

Pagni, Pedro A.; Bueno, Sinésio F.; Gelamo, Rodrigo P. (Orgs.). Biopolítica, arte de viver e educação. Marília: Oficina Universitária; São Paulo: Cultura Acadêmica, 2012.

PaIva, Antonio C. S. Sujeito e laço social: a produção da subjetividade na arqueogenealogia de Michel Foucault. Rio de Janeiro: Relume-Dumará; Fortaleza: Secretaria de Cultura e Desporto do Estado, 2000. 
Paraíso, Marlucy A. Pesquisas pós-críticas em educação no Brasil: esboço de um mapa. Cadernos de Pesquisa, São Paulo: Fundação Carlos Chagas, v. 34, n. 122, p. 283-303, 2004. Passetti, Edson (Coord.). Kafka-Foucault. sem medos. Cotia: Ateliê Editorial, 2004. Passos, Izabel C. F. (Org.). Poder, normalização e violência: incursões foucaultianas para a atualidade. Belo Horizonte: Autêntica, 2008.

; Belo, Fábio R. R. (Orgs.). Na companbia de Foucault: 20 anos de ausência. Belo Horizonte: FALE/UFMG, 2004.

Pereira, Antônio. A analítica do poder em Michel Foucault. a arqueologia da loucura, da reclusão e do saber médico na Idade Clássica. Belo Horizonte: Autêntica; FUMEC, 2003. Pey, Maria O.; Bacca, Ana M.; SÁ, Raquel S. Nas pegadas de Foucault: apontamentos para a pesquisa de instituições. Rio de Janeiro: Achiamé, 2004.

Portocarrero, Vera. As ciências da vida: de Canguilhem a Foucault. Rio de Janeiro: Fiocruz, 2009.

Prado Filho, Kléber. Michel Foucault. uma história da governamentalidade. Rio de Janeiro: Insular; Achiamé, 2006a.

Michel Foucault uma história política da verdade. Rio de Janeiro: Insular; Achiamé, 2006b.

Queiroz, André. Foucault. o paradoxo das passagens. Rio de Janeiro: Pazulin, 1999. O presente, o intolerável... Foucault e a história do presente. Rio de Janeiro: 7Letras, 2004.

.; Cruz, Nina Velasco e (Orgs.). Foucault hoje? Rio de Janeiro: 7Letras, 2007.

RAGo, Margareth. O efeito-Foucault na historiografia brasileira. Tempo Social, São Paulo: FFLCH/USP, v. 7, n. 1-2, p. 67-82, out. 1995.

Foucault, história e anarquismo. Rio de Janeiro: Achiamé, 2004.

.; Orlandi, Luiz B. L.; Veiga-Neto, Alfredo (Orgs.). Imagens de Foucault e Deleuze: ressonâncias nietzschianas. Rio de Janeiro: DP\&A, 2002.

.; Veiga-Neto, Alfredo (Orgs.). Figuras de Foucault. Belo Horizonte: Autêntica, 2006.

; __. (Orgs.). Para uma vida não fascista. Belo Horizonte: Autêntica, 2009.

Ratto, Ana L. S. Livoros de ocorrência: (in)disciplina, normalização e subjetivação. São Paulo: Cortez, 2007.

Resende, Haroldo (Org.). Michel Foucault: transversais entre educação, filosofia e história. Belo Horizonte: Autêntica, 2011.

Ribeiro, Renato J. (Org.). Recordar Foucault: os textos do Colóquio Foucault. São Paulo: Brasiliense, 1985.

Rocha, José M. S. Michel Foucault e o direito. Rio de Janeiro: Forense Universitária, 2011. RodRigues, Heliana B. C.Um (bom?) departamento francês de ultramar: Michel Foucault no Brasil, 1965. Mnemosine, Rio de Janeiro: UERJ, v. 6, n. 2, p. 186-203, 2010. 
Michel Foucault no Brasil: esboços de história do presente. Verve, São Paulo: PUC, n. 19, p. 93-112, 2011.

Rosa, Marilene; Torres, Magda; Rocha, Luciano (Orgs.). Experimentadores: Michel Foucault e práticas historiográficas. Rio de Janeiro: Paju, 2011.

SAmpaio, Simone S. Foucault e a resistência. Goiânia: UFG, 2006.

Sargentini, Vanice; Navarro-Barbosa, Pedro (Orgs.). Foucault e os domínios da linguagem: discurso, poder, subjetividade. São Carlos: Claraluz, 2004.

Scavone, Lucila; Alvarez, Marcos C.; Miskolci, Richard (Orgs.). O legado de Foucault. São Paulo: Edunesp, 2006.

Seção Especial Temática Educar como arte de governar. Currículo sem fronteiras, v. 11, n. 1, p. 5-136, jan./jun. 2011.

Seção Temática Governamentalidade e educação. Educação E̋ Realidade, Porto Alegre, v. 34, n. 2, p. 13-201, jan./jun. 2009.

Silva, Tomaz T. (Org.). O sujeito da educação: estudos foucaultianos. Petrópolis: Vozes, 1994.

. (Org.). Alienígenas na sala de aula: uma introdução aos estudos culturais em educação. Petrópolis: Vozes, 1995.

(Org.). Liberdades reguladas: a pedagogia construtivista e outras formas de governo do eu. Petrópolis: Vozes, 1998.

O currículo como fetiche: a poética e a política do texto curricular. Belo Horizonte: Autêntica, 1999.

Mapeando a [complexa] produção teórica educacional. Currículo sem Fronteiras, v. 2, n. 1, p. 5-14, 2002.

.; Moreira, Antonio F. (Orgs.). Territórios contestados: o currículo e os novos mapas políticos e culturais. Petrópolis: Vozes, 1995.

Silveira, Rafael A. Michel Foucault: poder e análise das organizações. Rio de Janeiro: FGV, 2005.

Soler, Rodrigo D. V. Michel Foucault e a ética do cuidado de si: desdobramentos históricos e desterritorialização da subjetividade. São Paulo: Baraúna, 2010.

Souza, Luiz A. F.; Sabatine, Thiago T.; Magalhães, Boris R. (Orgs.). Michel Foucault: sexualidade, corpo e direito. Marília: Oficina Universitária; São Paulo: Cultura Acadêmica, 2011.

Souza, Pedro de. Michel Foucault: o trajeto da voz na ordem do discurso. Campinas: RG, 2009.

Souza, Sandra C. A ética em Michel Foucault: a verdade, o sujeito, a experiência. Belém: Cejup, 2000.

Tema em Destaque Biopolítica, governamentalidade e educação. Cadernos de Pesquisa, São Paulo: Fundação Carlos Chagas; Campinas: Autores Associados, v. 42, n. 145, p. 12-65, jan./abr. 2012.

Ternes, José. Michel Foucault e a idade do homem. Goiânia: UCG; UFG, 1998. 
Teshainer, Marcus. Psicanálise e biopolítica: contribuição para a ética e a política em Michel Foucault. Porto Alegre: Zouk, 2006.

Tronca, Ítalo (Org.). Foucault vivo. Campinas: Pontes, 1987.

VALEIRÃo, Kelin. Foucault na educação. Pelotas: UFPel, 2010.

Vasconcellos, Jorge; Castelo Branco, Guilherme (Orgs.).Arte, vida e politica: ensaios sobre Foucault e Deleuze. Rio de Janeiro: LCV, 2010.

Vasconcelos, José G.; Magalhães Júnior, Antonio G. (Orgs.). Um dispositivo chamado Foucault. Fortaleza: LCR, 2002.

VAz, Paulo. Um pensamento infame: história e liberdade em Michel Foucault. Rio de Janeiro: Imago, 1992.

Veiga-Neto, Alfredo (Org.). Crítica pós-estruturalista e educação. Porto Alegre: Sulina, 1995.

Foucault E̊ a educação. Belo Horizonte: Autêntica, 2003.

Dicas... Revista Aulas, Campinas: UNICAMP, n. 7, p. 11-23, 2010.

; Fischer, Rosa M. B. Foucault, um diálogo. Educação E Realidade, Porto Alegre: UFRGS, v. 29, n. 1, p. 7-25, jan./jun. 2004.

Vergueiro, Laura. Presença foucaultiana. Discurso, São Paulo: USP, n. 10, p. 95-100,1979.

VEYNE, Paul. Como se escreve a história; Foucault revoluciona a história. Brasília: UnB, 1982.

Foucault: seu pensamento, sua pessoa. Rio de Janeiro: Civilização Brasileira, 2011.

VIEIRA, Priscila P. Michel Foucault e a história genealógica em Vigiar e punir. Campinas: IFCH/UNICAMP, 2006.

VIeIra, Ronaldo. Foucault em casa: aspectos discursivos da construção da comunidade sul-americana de nações (2004-2006). Brasília: FUNAG, 2010.

Winter, Célia A. F. C. Confissão e cura: uma interlocução entre Foucault e a psicanálise freudiano-lacaniana. Curitiba: Juruá, 2006.

Yazbeк, André C. 10 lições sobre Foucault. Petrópolis: Vozes, 2012.

\section{SOBRE O AUTOR}

Julio Groppa Aquino é doutor em psicologia escolar e desenvolvimento humano pela Universidade de São Paulo (USP). Professor associado da mesma instituição.

E-mail: groppaq@usp.br

Recebido em junho de 2012

Aprovado em setembro de 2012 


\section{JULIO GROPPA AQUINO}

\section{A difusão do pensamento de Michel Foucault na educação brasileira: um itinerário bibliográfico}

O presente artigo tem o propósito de configurar um horizonte possível da difusão do pensamento de Michel Foucault na literatura educacional brasileira, por meio da focalização de duas grandes frentes escriturais: os livros e os artigos divulgados em 15 periódicos da área, no período entre 1990 e 2012. No segundo caso, fulcro da investigação levada a cabo, foram selecionados 132 artigos que tomaram o pensamento foucaultiano como modo de trabalho, tendo sido analisados segundo: sua frequência e cronologia; a filiação institucional dos autores, bem como o rol dos mais assíduos; as obras de Foucault mais referidas; as temáticas e os tópicos teóricos mais visitados; por fim, os tipos investigativos empregados nas argumentações. As reflexões finais do artigo apontam para a exigência de perspectivar, para além da difusão, os múltiplos modos de apropriação das ideias do pensador no campo educacional brasileiro e, portanto, a diversidade de efeitos daí decorrente.

Palavras-chave: Michel Foucault; literatura educacional; difusão de ideias.

The diffusion of Michel Foucault's thought in the brazilian educational literature: a bibliographical itinerary

This article aims at setting up a possible horizon of the diffusion of Michel Foucault's thought in the brazilian educational literature, by focusing on two major writing fronts: books and articles published in 15 journals from 1990 to 2010. In the latter case, the core of this research, we selected 132 articles that took the foucauldian thought as a work method and analyzed them according to: their frequency and chronology; the institutional affiliation of the authors, as well as the list of the most frequent ones; Foucault's most cited works; the most visited 
themes and theoretical topics; and finally the investigative types used in the arguments. The final thoughts of this article point to the need to envisage, beyond the diffusion, the multiple modes of appropriation of the ideas of the French thinker in the brazilian educational field and, thus, the diversity of effects produced by them.

Keywords: Michel Foucault; educational literature; diffusion of ideas.

\section{La difusión del pensamiento de Michel Foucault en la literatura educacional brasileña: un intinerario bibliográfico}

Este articulo tiene el propósito de configurar un posible horizonte de la difusión del pensamiento de Michel Foucault en la literatura educacional brasileña, por medio de la focalización de dos grandes frentes de escritura: los libros y los artículos divulgados en 15 periódicos del área, en el periodo entre 1990 y 2012. En el segundo caso, punto crucial de la investigación, se han seleccionado 132 articulos que tomaron el pensamiento de Foucault como modo de trabajo y cuyo análisis se ha hecho teniendo en cuenta frecuencia y cronología; filiación institucional de los autores, como también el rol de los más asiduos; las obras de Foucault más referidas; las temáticas e los tópicos teóricos más visitados; y por fin, los tipos investigativos empleados en las argumentaciones. Las reflexiones finales del artículo señalan la exigencia de poner en perspectiva, más allá de la difusión, los múltiples modos de apropiación de las ideas del pensador en el campo educacional brasileño y, por consiguiente, la diversidad de efectos que resulta de ellos.

Palabras clave: Michel Foucault; literatura educacional; difusión de ideas. 